\title{
CANTOS E GRITOS DA TERRA: CAMPESINOS E PROPRIETÁRIOS RURAIS NOS PROCESSOS DE REFORMA E CONTRARREFORMA AGRÁRIA DO CHILE (1958-1990)
}

\author{
Vanderlei Vazelesk Ribeiro ${ }^{1}$
}

\begin{abstract}
RESUMO
Neste trabalho discute-se o processo de reforma e contrarreforma agrária, ocorrido no Chile entre as décadas de 1960 e 1990. Reflete-se, inicialmente, a respeito do processo de reforma agrária desenvolvido durante as presidências de Jorge Alessandri (1958-1964), Eduardo Frei (1964-1970) e Salvador Allende (1970-1973). Posteriormente, avalia-se o esforço de reversão do processo executado durante o regime liderado pelo general Augusto Pinochet entre 1973 e 1990. Entende-se estes processos como resultado da interação entre a burocracia de Estado e os diversos grupos sociais. Deste modo, analisa-se "a atuação tanto de organizações representativas dos proprietários de terra como dos movimentos campesinos." Procuraremos perceber estes movimentos não como todos homogêneos, mas observando suas divergências internas, que levam, às vezes, a fraturas intraorganizacionais. Quando possível realiza-se a comparação do desenvolvimento da reforma e da contrarreforma, cotejando seu desenrolar no Chile central e na Região Sul, marcada pelos conflitos entre os terratenentes e as populações mapuches, na luta pela posse da terra. Deste modo, compreende-se o peso do tema indígena nesta região, que teria reflexos no contexto nacional.
\end{abstract}

Palavras-chave: Estado. Movimentos campesinos. Representação terratenente.

\section{CHANTING AND SHOUTING FROM THE LAND: PEASANTS AND LAND OWNERS IN CHILIAN AGRARIAN REFORM AND COUNTER REFORMS PROCESS (1958-1990)}

\begin{abstract}
In this work is discussed the process of agrarian reform and counter agrarian reform occurred in Chile between 1960 and 1990. Initially there is a reflection about the agrarian reform process developed during the government of Jorge Alessandri (1958-1964), Eduardo Frei (1964-1970) and Salvador Allende (1970-1973). In sequence, there is an evaluation on the effort for reversion of the executed process during the regime led by general Augusto Pinochet between 1973 and 1990. The aim is not to comprehend the movements as homogeneous, but to observe their internal divergences which sometimes lead to interorganizational breaks. On occasion, there will be compared the agrarian reform and counter reform development in central and south Chile, among the conflicts between landowners and mapuche population in the struggle for land ownership. In this way we are able to weight the indigenous theme in this region, which would lead to consequences in the national landscape.
\end{abstract}

Keywords: State. Peasant movements. Landowner representation.

Data de submissão: 25.04 .2021

Data de aprovação: 24.05.2021

\section{INTRODUÇÃO}

Em março de 1974, escrevendo desde Tomé, província de Concepción, Victor Bárbaro Campos solicitou à Corporación de Reforma Agraria (CORA) a devolução de suas terras, que

\footnotetext{
1 Doutor em História pela Universidadde Federal Flumense. Professor de História da América Latina da Universidade Federal do Estado do Rio de Janeiro (Unirio). E-mail: vvazelesk@ gmail.com
} 
haviam sido expropriadas, em 1972. Embora as tivesse oferecido para expropriação a fim de receber a indenização a que teria direito mais rapidamente, alegava ter sido expropriado à força pelos comunistas do governo deposto. A argumentação de Victor Bárbaro coincidia com páginas da Revista El Campesino, órgão da Sociedad Nacional de Agricultura (SNA) entidade representativa dos proprietários rurais chilenos - que afirmara que os fazendeiros sofriam tal pressão do governo. Victor Bárbaro, de fato, recebeu a terra e a indenização.

Em setembro de 1975, Robinson Moira Boaventura e Irenio Nuñes Leiva pediram à CORA a devolução das terras que lhes haviam sido expropriadas em 1966, ainda no governo do democrata-cristão Eduardo Frei. Usaram o mesmo argumento de Victor Bárbaro, ao afirmar que estavam sendo pressionados ao tempo da expropriação e que, recuperando suas terras, trabalhariam para apoiar a reconstrução de seu país, que fora "resgatado" pelos militares, das mãos comunistas. Teriam, contudo, de aguardar melhores dias. As terras que compraram em Rancagua eram parte de uma extensa propriedade pertencente a Dom Eleodoro Callos, que a dividira com a mulher, Josefina Prado, a filha do casal, Maria Josefina Prado, e o genro, Eduardo Varela. Posteriormente todos vendiam parcelas, como as que os missivistas haviam comprado. O problema é que justamente em abril de 1966, quando eles fizeram essa compra, foi publicada uma lei que proibia o parcelamento de terras sem autorização da CORA ${ }^{2}$. Esses dois exemplos nos mostram a complexidade do processo de reforma agrária ocorrido no Chile durante o período em análise.

Aparentemente, o golpe empresarial-militar, que derrocou a experiência democráticosocialista, teve um caráter fulminante no processo de revisão da reforma agrária. Entretanto, o que observaremos é que apesar da vigorosa repressão, as avaliações foram feitas quase caso a caso, como lembrou Pablo Baraona, um ex-expropriado, que se tornou ministro da economia de Augusto Pinochet (OVALLE, 2013, p. 215). Neste trabalho avaliaremos o processo de reforma agrária chilena em dois momentos: o primeiro entre a aprovação da lei 15.020 até o golpe de Estado liderado pelo general Augusto Pinochet, em 1973; e o segundo durante o regime empresarial-militar, que se estendeu até 1990. Evidentemente, para introduzir o tema será necessária uma discussão acerca do período anterior à aprovação da referida lei, uma vez que os temas da reforma agrária e das relações sociais campesinas no Chile estavam presentes na agenda política do país pelo menos desde a década de 1930. Buscaremos perceber a variedade dos processos que se desenvolveram por todo este período. Observaremos a emergência dos movimentos campesinos que contaram com apoio dos setores vinculados aos partidos Democrata Cristão, Socialista e Comunista, bem como com a articulação dos terratenentes ${ }^{3}$, organizados não só em suas entidades de classe, como por meio da SNA e do Consorcio de Sociedades Agrícolas del Sur (CAS) e também com o apoio dos partidos Conservador e Liberal, mais tarde fundidos no Partido Nacional. Além disso, sempre que possível, estabeleceremos as distinções entre o Chile central, berço da conquista espanhola, e o sul do país, onde a presença mapuche se fez sentir na ampliação da luta pela terra, quando os autóctones buscaram reconquistar as áreas perdidas, sendo também palco de vivíssima repressão pela parceria público-privada que envolveu militares das forças armadas, corpo de carabineiros (polícia militar chilena) e terratenentes locais. Deste modo, o leitor viajará pelo "País da Geografia Louca", avaliando os esforços por realizar uma reforma agrária, bem como as tentativas de evitá-la ou revertê-la.

\footnotetext{
${ }^{2}$ O Processo de Victor Bárbaro Campos pode ser Encontrado em Servicio Agrícola y Ganadero, Concepción carpeta 1748. Quanto ao de Eusebio e Irenio pode ser revisado em: Servicio Agrícola y Ganadero, Rancagua, Carpeta 1354. Neste arquivo, localizado em Santiago do Chile, encontram-se os processos de expropriação das terras durante a reforma agrária e de parcelamento dos lotes após o golpe de 1973.

${ }^{3}$ Utilizamos a expressão terratenentes mais comum na língua espanhola, por entendermos que a mesma representa bem o sentido da concentração de terras em toda América Latina.
} 


\section{REFORMA AGRÁRIA (1958-1973)}

O ano era 1958 e o Chile tinha previsto eleições presidenciais. As elites políticas orgulhavam-se, pois há um quarto de século o país era governado por presidentes eleitos e o parlamento funcionava. Aquela eleição, entretanto, seria diferente, tendo em vista as mudanças que a marcariam: primeiramente, o Partido Comunista (PC), que fora posto na ilegalidade dez anos antes, por meio da chamada "Lei Permanente de Defesa da Democracia", voltava à cena eleitoral, compondo com os socialistas a Frente Revolucionaria de Acción Popular (FRAP), apoiando o já experiente senador Salvador Allende; além disso, a entrega das cédulas eleitorais só seria feita no momento da votação (AVENDAÑO, 2017, p. 136). Todas essas mudanças tiveram impacto decisivo no meio rural. Desde seu nascimento, em 1921, o PC levantava as bandeiras da reforma agrária, da restituição das terras aos mapuches - que desde o fim do século XIX eram expropriados, por meios legais ou não - e o estabelecimento de condições adequadas de trabalho no campo. $O$ fato de a cédula ser entregue no local da votação não impedia, mas dificultava as fraudes eleitorais comuns no Chile profundo (OSZLAK, 2016, p. 156).

Deste modo, os temas ligados ao mundo rural retornaram fortemente ao cenário político, ainda que Jorge Alessandri, candidato oligárquico, tenha vencido por trinta mil votos o candidato esquerdista. Utiliza-se o verbo retornar pois desde os anos vinte o setor proprietário rural chileno, embora controlasse o parlamento e mantivesse firme aliança com setores do comércio e da Indústria - através da Confederación de la Producción y comercio (CPC), vinha sendo questionado por causa das duras condições sociais dos trabalhadores do Chile central e do Sul ${ }^{4}$, tendo em vista o problema mapuche. Entre 1866 e 1884, num longo processo de "pacificação" paralelo à "conquista del Desierto", realizada pela oligarquia argentina, militares e terratenentes chilenos subjugaram os mapuche, que desfrutavam de autonomia desde os dias da conquista, tendo estabelecido um tratado com os espanhóis em 1641, renovando-o com o Estado chileno, em 1825. Entretanto, a ideia de que havia um "vazio demográfico" a explorar - similar ao que se pensava da Amazônia em países como o Brasil ou Peru - ganhou corpo em meados do século XIX; ali estaria uma terra vazia, onde o que havia eram índios "preguiçosos".

Completado o processo de conquista, a ampla densidade populacional obrigou o Estado a reconhecer a existência de populações e a necessidade de radicá-las em comunidades tituladas em nome de um cacique local, ainda que em áreas diminutas. Entretanto, muitas vezes a terra era titulada em favor de gente vinda do Chile Central ou até mesmo de outros países, como Alemanha, França e Suíça. Em vários casos, os títulos se sobrepunham a áreas anteriormente destinadas aos indígenas e estes eram expulsos violentamente. Em outras situações eram levados a assinar falsos contratos de arrendamentos por noventa e nove anos, depois registrados como compras nos cartórios locais. Deste modo, os confrontos entre colonos e mapuches tornaram-se comuns (CORRÉA, 2005, p. 121; BENGOA, 2014, p. $67-$ $85)$.

A questão da produtividade agrícola também deve ser levada em conta, uma vez que os tempos em que a agricultura chilena conseguia abastecer também o Peru - durante a época colonial - e que o trigo chileno alimentava também mineiros na Califórnia e na Austrália, em meados do século XIX, haviam há muito terminado. Existiam esforços por parte dos dirigentes da SNA, no início do século XX, no sentido de aperfeiçoar a produtividade

\footnotetext{
${ }^{4}$ Dona Alicia Muñoz, atual dirigente da Asociación Nacional de Mujeres Rurales e Indígenas (ANAMURI), nascida no Fundo Agua Fría, em Maule, centro-sul do país, contou-me, em entrevista, que trabalhava como doméstica dos patrões e que recorda até hoje da péssima qualidade dos biscoitos e do macarrão oferecidos por eles aos campesinos. Entrevista inédita ao autor realizada em 10 de julho de 2017, na sede da ANAMURI em Santiago do Chile.
} 
agrícola, mas o fato é que a agricultura chilena não exportava nem alimentava o crescente mercado urbano interno, uma vez que sofria a concorrência do trigo e do vinho argentinos, levando o Chile a ser um importador de alimentos (ULLOA, 2006, p. 57).

Todos esses temas ganharam relevância na cena política a partir da crise de 1929, uma vez que o país havia perdido o mercado salitreiro para seu similar sintético desenvolvido pelos alemães, e o cobre, explorado desde o século XVIII, teria de esperar a eclosão da Segunda Guerra Mundial para retornar à projeção anterior. Os resultados da crise não se fizeram esperar: o ditador Carlos Ibañes, que chegou ao poder em 1927, foi destituído em 1931, acarretando um período de intensa instabilidade que durou dezoito meses e que incluiu a proclamação de uma República Socialista de duas semanas de vigência, sob a liderança do Major Marmaduke Grove. A situação política se reequilibraria a partir do retorno do presidente Arturo Alessandri, em 1932 (ele governara o país entre 1920 e 1924 e entre março e outubro de 1925) (BENGOA, 2014, p. 65; OLIVARES, 2019, p. 235).

Enquanto os representantes da SNA brigavam no parlamento contra as medidas trabalhistas e se queixavam da baixa remuneração para seus produtos, os comunistas e socialistas iam ao meio agrário tentar organizar sindicatos e sofriam a viva resistência patronal. Os socialistas chegaram a criar a Liga Nacional de Defesa dos Campesinos Pobres em 1935, com eco maior em Santiago, e os comunistas procuravam organizar sindicatos, também na região metropolitana, explorando a experiência de atuação sindical dos mineiros do Norte (ROJAS, 2015, p. 23).

Do ponto de vista dos setores terratenentes, a situação agravou-se em 1938 face à vitória de Pedro Aguirre Cerda, que liderava uma coligação que unia os partidos Radical, Socialista e Comunista. A sindicalização rural, permitida, mas não regulamentada, ganhava seu maior impulso desde a implantação do código do trabalho, em 1931, em virtude da atuação dos comunistas e, em menor medida, dos socialistas. A resposta terratenente foi sentida de todas as formas: desde a expulsão de camponeses sindicalizados ou que tivessem votado na candidatura radical, com um irônico, "vá pedir trabalho a Aguirre Cerda", até o sequestro de inspetores do trabalho, agora mais atuantes, apoiando sindicalistas que, por sua vez, levantavam pautas reivindicatórias. Por outro lado, em maio de 1939 os terratenentes organizaram um congresso de agricultores ${ }^{5}$, no qual solicitavam ao presidente a suspensão da sindicalização dos camponeses até que uma nova lei fosse editada, pedido que foi atendido.

De acordo com Loveman (1976, p. 23), havia, ao final de 1939, 219 sindicatos organizados na zona metropolitana de Santiago. A proibição, entretanto, não pôde afetar os sindicatos já organizados legalmente, valendo o princípio de que a lei não pode retroagir para cassar direitos, embora os proprietários se esforçassem vigorosamente para impedir a atuação dos sindicalistas no campo. Jaime Larraín e outros dirigentes da SNA afirmavam que a existência de um sindicato na fazenda representaria, literalmente, um contrapoder na casa do patrão. Não percebendo o camponês como um cidadão titular de direitos, mas sim como uma eterna criança a ser governada, perguntavam-se a quem o trabalhador obedeceria, se ao patrão ou ao sindicato (OLIVARES, 2019, p. 321).

Como alternativa, os dirigentes da SNA ofereciam uma espécie de bondade patronal, pela qual os patrões fossem generosos, atendessem os camponeses no que fosse possível, combatessem o alcoolismo e a tuberculose e realizassem festas domingueiras. Essa ideia de uma sociedade rural harmônica, tão presente nos discursos das sociedades rurais argentina e brasileira, bem como na nossa música caipira $^{6}$, seria reiterada ao longo de décadas pelos dirigentes da Sociedade Nacional de Agricultura. O campo seria um lugar de paz e esta paz só

\footnotetext{
${ }^{5}$ No Chile, os fazendeiros autodenominam-se agricultores.

6 "Este pedacinho de chão encantado foi abençoado por nosso Senhor! Que nunca nos deixa faltar no sertão: saúde, união, a paz e o amor!" Tião Carreiro, canção "Encantos da natureza".
} 
poderia ser quebrada por agentes externos: comunistas, inspetores do Ministério do Trabalho e socialistas.

Com a morte de Pedro Aguirre Cerda antes de completar seu mandato e sem atender ao pedido dos dirigentes da SNA no sentido de proibir até mesmo os sindicatos já existentes, assume a presidência, após ser eleito, o também radical Juan Antonio Rios. Durante seu governo (1941-1945), o panorama não se alterou. No Chile central, os comunistas esforçavam-se para mobilizar os camponeses por direitos trabalhistas, criando a Federación Nacional de Trabajadores Agrícolas, além da Asociación Nacional de Pequeños Agricultores (OLIVARES, 2019, p. 432). Ao Sul, os mapuches, que em sua maioria haviam votado em Pedro Aguirre Cerda e criado a Frente Popular Araucana, como um reflexo da Frente Popular que o levara ao poder, continuavam sofrendo a espoliação de suas terras. Sob a liderança de Venancio Corioepán, que se elegeu deputado em 1942, (já havia deputados mapuches desde a década de 1920), criou-se a Corporación Araucana, emulando a Corporación de Fomento, que era fundamental no processo de industrialização. Esta entidade buscava, entre outras melhorias, abrir estradas que conectassem as comunidades às cidades próximas, visto que os proprietários muitas vezes não lhes permitiam passar por suas terras (BENGOA, 2014, p. 168).

Por sua vez, a já centenária SNA (fora criada em 1838) passou a enfrentar concorrência. Ainda que contasse com a Rádio Agricultura, fundada em 1936, e que foi ao longo das décadas replicada pelo país e embora tenha mudado o nome de sua revista de $E l$ Agricultor para El Campesino, sua atuação era percebida por seus pares como extremamente favorável apenas aos tradicionais cerealistas do Chile central e pouco atenciosa aos modernos fruticultores e principalmente aos pecuaristas do Sul. Assim, em 1944, foi criado em Temuco o Consorcio de Sociedades Agrícolas del Sur, que sem necessariamente desconectar-se de Santiago, buscava uma atuação mais autônoma face à SNA (OSZLAK, 2016, p. 132).

Quanto à sua atuação, a SNA continuava lutando para bloquear a sindicalização rural e se queixava do protecionismo que era estruturado em favor da indústria, enquanto a agricultura sofria o tabelamento de seus preços ao mesmo tempo em que pagava caro pelos insumos necessários à sua produção. De acordo com Ulloa (2006, p. 44), a exclusão dos camponeses do direito à sindicalização seria um acordo que possibilitaria o processo de industrialização por substituição de importações, já que, sendo o setor agrário penalizado face aos baixos preços dos produtos agrícolas, os fazendeiros descarregariam seus prejuízos sobre seus trabalhadores, pagando-lhes ínfimas remunerações. Este acordo teria contado, inclusive, com o apoio dos comunistas, que aceitaram a exclusão dos rurais em troca de benefícios aos trabalhadores urbanos. Entretanto, ao avaliarmos o trabalho bem documentado de Maria Angélica Olivares, percebe-se que a militância do PC manteve, bem mais do que o Partido Socialista (PS), um empenho no sentido de incluir os rurais na legislação trabalhista e lutar pela reforma agrária durante o período 1938-1948, quando foram excluídos "legalmente" do sistema político. Isso pode ser melhor observado em 1946, quando, devido ao falecimento do presidente Juán Antonio Ríos, uma aliança entre radicais e comunistas leva ao poder Gabriel González Videla que, por sua vez, nomeou comunistas para Ministérios, inclusive para o Ministério da Agricultura. Neste período, o PC visou derrubar na prática a proibição à sindicalização, enquanto no governo, homens como o mapuche Juán Chacon Corona, buscavam liberar a importação do trigo argentino para competir com o trigo nacional açambarcado pelos terratenentes. A reação destes, que ampliavam a SNA criando o Comitê de Relacionamento de Entidades Agrícolas, repetia o padrão de expulsão dos sindicalizados e de firmar uma parceria público-privada com carabineiros e com os inspetores do trabalho, barrando a atuação de sindicalistas, além de fazer uma vigorosa campanha anticomunista nos meios de comunicação. 
No parlamento, a aprovação de uma lei de sindicalização rural, que impediu os analfabetos de se sindicalizarem, manteve os sindicatos limitados às fazendas, proibindo a formação de federações e confederações. Determinou ainda que o proprietário da fazenda fosse também o tesoureiro do sindicato, que era necessário que os sindicalizados já estivessem trabalhando na fazenda há pelo menos um ano - algo difícil quando a inquilinaje ${ }^{7}$ já se reduzia - e praticamente proibiu as greves. O complemento desta medida foi tomado em julho de 1947, em votação pelo parlamento, na qual os partidos Conservador e Liberal, firmemente ligados aos proprietários, excluíram os comunistas da cena política decretando a ilegalidade do Partido, que tanto batalhava pela sindicalização rural (OLIVARES, 2019, p. 523).

O período compreendido entre 1948 e 1952 pareceu de paz para os terratenentes, pois dedicaram-se ao questionamento dos baixos preços de seus produtos e aprovaram uma lei de privatização das águas de rios que passassem por suas propriedades, transformando-os, em 1951, também em aguatenentes. Porém, logo o tema agrário retornaria à cena, uma vez que nas eleições de 1952, o ex-ditador Carlos Ibánez voltou ao poder, prometendo a reforma agrária, com apoio dos ilegalizados comunistas.

O projeto de reforma agrária foi facilmente derrotado no parlamento, mas os comunistas organizaram clandestinamente, em 1953, uma conferência de trabalhadores agrícolas, na qual foi reivindicada a devolução das terras aos mapuches, além da reforma agrária e da criação de uma legislação trabalhista (PERALTA, 2006, p. 17). Entretanto, para os terratenentes, o pior ainda estava por vir: no fim dos anos de 1930, a Igreja Católica tentou organizar sindicatos, mas a pressão direta da SNA sobre os bispos tornou sua atuação inviável. No início dos anos 1950, a Arquidiocese de Santiago criou a Fundación de Educación Sindical e a Acción Sindical y Económica chilena, que buscavam apoiar a sindicalização dos trabalhadores rurais. Deste modo, a Igreja Católica foi ao campo disputar espaço com os comunistas, assim como fazia no Brasil nessa mesma época. Para tanto era preciso apoiar reivindicações e, na zona de La Molina, em 1953, ocorreu uma greve que uniu católicos progressistas e comunistas. A ameaça, feita pelo arcebispo metropolitano de Santiago, de promover uma coleta em todas as missas de domingo em favor dos grevistas acuou o governo que, por sua vez, pressionou os proprietários rurais. O governo ameaçou retirar os carabineiros de La Molina, enquadrar os fazendeiros, utilizando contra eles a Lei de Defesa da Democracia e, pior que tudo, sobretaxar o vinho exportado. Deste modo, não foi possível utilizar as velhas estratégias contra os grevistas. Os terratenentes sofriam sua primeira derrota simbólica.

O período entre 1954 e 1958 marcou o crescimento, na sociedade chilena, da noção de que a agricultura era o nervo exposto da economia, uma vez que não exportava e que não alimentava a sociedade, cada vez mais urbana. O cobre, portanto, continuaria como a principal fonte de divisas do país. Assim, mudanças eram urgentes. Os proprietários se defendiam afirmando que os problemas estavam na falta de crédito e de estradas, alegando que se produzissem tudo o que podiam, a maior parte apodreceria no campo (AVENDAñO, 2017, p. 87).

De acordo com Ulloa (2006, p. 35) e Ovalle (2013, p. 25), as críticas ao setor agrário não vinham apenas da esquerda, mas também de setores da indústria e até mesmo dos conservadores. A noção de que agricultura tinha de mudar e que essa mudança teria de passar pelo tema da propriedade da terra, ganhava corações e mentes antes mesmo das eleições de 1958.

Jorge Alessandri assumiu o poder com uma plataforma liberal, pedindo aos industriais que aceitassem perder a proteção alfandegária da qual desfrutavam havia duas décadas. $\mathrm{Na}$

\footnotetext{
${ }^{7} \mathrm{O}$ sistema de inquilinaje chileno era similar a tantos sistemas de trabalho na América Latina: o camponês trabalhava tantos dias de graça para o patrão e, em troca, tinha direito, dependendo sempre de sua vontade, ao cultivo de um pedaço de terra e pastos para seus animais.
} 
realidade, os proprietários rurais, embora criticassem a proteção à indústria, desejavam-na para si, pois "a agricultura não está abandonada, mas desamparada!", afirmavam os dirigentes da SNA (OSZLAK, 2016, p. 143). Entretanto, uma série de fatores externos e internos entrecruzaram-se, acelerando o início do processo de reforma agrária. Externamente, a Revolução Cubana, de 1959, e sua radical reforma agrária, que criou milhares de pequenos proprietários $^{8}$, significou a esperança para a esquerda e o pânico entre setores de direita. Nos Estados Unidos, as duras condições de trabalho no campo chileno eram criticadas, especialmente quanto à quase total impossibilidade de sindicalização. Para complicar a situação dos terratenentes, em 1961, após um mega terremoto atingir a cidade de Valdivia, o governo de Jorge Alessandri pediu ajuda aos EUA que, sob a administração Kennedy - a qual patrocinava a chamada Aliança para o Progresso - condicionou o empréstimo à aprovação de uma lei de reforma agrária ${ }^{9}$. Além disso, a vitória dos radicais nas eleições parlamentares de março de 1961 levou o presidente a convidá-los a participar do governo. Entretanto, os radicais também condicionaram sua participação à elaboração de uma lei de reforma agrária. Os proprietários, dividiram-se entre os do Sul, que recusavam qualquer ideia de reforma que significasse a alteração na estrutura de propriedade privada, e os do Chile central, que em parte tendiam a aceitar algum tipo de mudança na tenência da terra. Numa tensa reunião da SNA era aprovada, por um voto de diferença, a não oposição à reforma.

Ainda em 1961, enquanto os comunistas mantinham o esforço para sindicalizar os camponeses, os mapuches continuavam batalhando na justiça para reaver suas terras, porém sem obter êxito. Mais recursos eram aprovados para que a Caja de Colonización pudesse subdividir as terras públicas e nelas instalar mais colonos, além de prorrogar, mais uma vez, a proibição de vendas de terras das comunidades indígenas radicadas, em sua maioria, no Sul do país ${ }^{10}$.

Finalmente, a lei 15.020, que permitia a realização de uma reforma agrária, foi aprovada no parlamento, em 1962. Como no Brasil - com a elaboração do Estatuto da Terra em 1964 - no Chile dois órgãos foram criados: a CORA e o Instituto de Desarrollo Agropecuario (INDAP). Aquela se encarregaria da divisão das terras e da instalação dos parceleiros, priorizando os que lá estavam. Este buscaria atuar de forma a trazer tecnologia para o meio agrário, bem como difundir a sindicalização no campo.

Em 1963, a constituição chilena foi emendada no sentido de que fosse permitido o pagamento de indenização para os expropriados em dez cotas anuais. A reforma de Jorge Alessandri, expressa na lei 15.020 de 1962 , criticada como de macetero ${ }^{11}$ (insuficiente) pela esquerda, de fato não estabeleceu um limite para o tamanho da propriedade rural, mas fixou o princípio de que uma propriedade mal explorada poderia ser expropriada. Se no governo de Jorge Alessandri poucas famílias foram beneficiadas pela ação da CORA, a situação mudaria dramaticamente no governo de Eduardo Frei (OSZLAK, 2016, p. 216). Um ator não convidado entrou em cena neste mesmo ano. No Chile central, o movimento camponês ainda

\footnotetext{
${ }^{8}$ No período entre 1959 e 1963, a reforma agrária cubana dividiu terras em propriedades individuais para pequenos cultivadores, criando cerca de cem mil parceleiros. Rapidamente, entretanto, para aproveitar especialmente a estrutura das plantações de cana-de-açúcar organizaram-se grandes áreas em cooperativas controladas pelo Estado (VASCONCELOS, 2017, p. 243).

${ }^{9}$ Tanto no Peru como no Chile, os proprietários rurais têm amargas memórias e queixas do período Kennedy. Para eles, os democratas americanos não aceitariam a concorrência de seus produtos no mercado estadunidense e por isso favoreciam reformas no continente (OTERO, 2007, p. 145; OVALLE, 2013, p. 216).

${ }^{10} \mathrm{O}$ tema das terras indígenas era espinhoso ao Sul: eram, como vimos, cedidas em lotes a um cacique, mas os comuneros tinham usufruto. Em 1927, aprovou-se a subdivisão das comunidades e, em vários decretos a partir desta data, proibiu-se a venda destas terras até a ditadura de Pinochet finalmente regularizar as propriedades individuais ao fim dos anos 1970 (BENGOA, 2014, p. 376).

11 Traduzindo do espanhol, a palavra macetero significa vaso de planta. A reforma era chamada de "macetero" pois acreditava-se que seu impacto seria limitado como o de plantas em vasos.
} 
não havia ganhado força apesar dos temores dos proprietários de terras. Ao Sul, com a bênção da machi (médium), os mapuches de Arauco realizavam, em 1962, suas primeiras ocupações de terras. O lema de "terra para quem nela trabalha" deixou muitos de fora, especialmente os mapuches (BENGOA, 2014, p. 235).

Em 1964, uma derrota para o socialista Oscar Naranjo nas eleições complementares para uma vaga de deputado, na província de Curicó, assustou os setores terratenentes, que pressentiram o perigo da vitória de Salvador Allende, novamente candidato à presidência da república pela FRAP. Por isso, abandonaram o radical Pedro Dum e canalizaram seus votos e de seus camponeses para Eduardo Frei. Entretanto, o candidato da Democracia Cristã disputava espaço não com a direita, mas com a esquerda. A revolução socialista opunha sua Revolução em Liberdade defendida pela Democracia Cristã e a um sistema coletivista, propunha assentamentos, que mais tarde, se converteriam em propriedades individuais.

A reforma agrária no Chile, como a peruana de Velasco Alvarado e a brasileira dos primeiros meses do governo Castello Branco, parecia ser a melhor vacina contra a revolução no estilo cubano. Desse modo, o governo chileno atuou de forma vigorosa, acelerando a expropriação de terras - dentro dos limites da lei de Jorge Alessandri -, derrubando, na prática, a lei de sindicalização rural, por meio dos promotores da Democracia Cristã, indo especialmente a zonas do Chile central para dinamizar a formação de sindicatos. Os proprietários estavam divididos, pois os do Sul inicialmente apoiaram Eduardo Frei, já que seu discurso de modernização os convenceu de que não seriam expropriados. Os do Centro, entretanto, entenderam que era necessário atuar mais fortemente contra a ação estatal, mas não encontraram apoio em outros setores proprietários, agindo então de forma mais defensiva, decidindo, por exemplo, pelo parcelamento de suas fazendas. Em 1966, uma lei proibiu tal prática, pois exigia prévia autorização da CORA. Enquanto isso, especialmente no Chile central, as greves começavam a ganhar magnitude.

Em 1967, três mudanças afetaram muito o meio agrário: em janeiro, a reforma constitucional, que aumentou para trinta anos o prazo de pagamento pela terra expropriada, ampliando as possiblidades do Estado para realizar este ato; em abril, foi aprovada a sindicalização campesina (os comunistas desejavam um sindicato único, mas a maioria democrata-cristã, que controlava o parlamento, impôs a pluralidade sindical, redundando na formação de múltiplas federações e confederações); e em julho, veio a lei 16.640, da reforma agrária. Pela referida lei, foi estabelecida uma área máxima de 80 hectares para a propriedade, que contasse com irrigação básica o que significava um apenas hectare físico em Santiago, mas que poderia chegar a quatro ou mais hectares no Sul, conforme o tipo de solo, se precisava ou não de irrigação etc. As áreas inferiores a este tamanho poderiam ser expropriadas, se mal exploradas ou abandonadas. As propriedades divididas entre 4 de novembro de 1964 e a data de publicação da referida lei e que não estivessem sendo cultivadas poderiam ser desapropriadas em até três anos. Tal fato desencadeou, em 1970, uma intensificação das expropriações, o que irritou os dirigentes da SNA. Arrendamentos eram permitidos, mas irregularidades nos contratos poderiam dar causa à expropriação (AVENDAÑO, 2017, p. 235; OSZLAK, 2016, p. 265).

Estas mudanças causaram profundas transformações em ambos os setores em análise. Do ponto de vista dos proprietários, seu mundo virara de cabeça para baixo, pois não agradava o fato de terem que negociar com aqueles que consideravam inferiores, ou seja, os camponeses; além de terem que aceitar inspetores do trabalho em suas terras. Ainda, relevar a perda de sua propriedade era extremamente difícil para eles. Não era só uma questão econômica, mas também a sensação de um mundo que conheciam que se desagregava. Os campesinos também viram seu mundo ser transformado, porém tais mudanças ocorreram em sentido oposto àquelas experimentadas pelos terratenentes. Podiam agora participar de greves, recorrer ao inspetor do trabalho e, quem sabe, até ter a propriedade da terra. Tais mudanças, 
contudo, beneficiavam mais os homens que as mulheres, já que, como nos recorda Eidi Tinsman, elas eram vistas apenas como mães e cuidadoras do lar. De todo modo, em 1968, os movimentos começaram a surgir.

Na fazenda Santa Marta, no Vale de Longotoma, região de Val Paraíso, uma greve, que durou meses, transformou-se em ocupação de terras. Os fazendeiros conseguiram organizar sua retomada prometendo dinheiro e mesmo um pedaço de terra aos camponeses aliados. Ao final, a terra acabou mesmo expropriada (SEGUEL, 2012, p. 45). Em San Estevan, província de Los Andes, mesma região de Val Paraíso, ainda em 1968, uma greve desdobrou-se em uma ocupação de terra dinamizada por militantes radicalizados do socialismo. Cristian Pérez, provavelmente, supervaloriza a ocupação da fazenda San Miguel, classificando-a como uma protoguerrilha chilena, mas o fato é que, efetivamente, houve jovens dirigentes socialistas que, impactados pelo mito da Revolução Cubana, imaginavam a possibilidade da luta armada a partir do campo (PÉREZ, 2000, p. 198).

O movimento campesino crescia e se diversificava. Os comunistas, por exemplo, que em 1961 haviam criado a Federación Campesina e Indígena, agora a batizavam Ranquil, compondo-a com os socialistas, evocando o massacre sofrido por campesinos chilenos e mapuches em 1934, na cidade sulista que dava nome à organização. Os democratas-cristãos estavam na Triunfo Campesino enquanto a Igreja Católica investia na Confederación Libertad. Uma cisão da Democracia-Cristã - o Movimiento de Acción Popular Unitario criou a Unión Obrera-Campesina, tendo a direita fundado a Provincias Agrarias Unidas. $\mathrm{O}$ Movimiento de Izquerda Revoluncionaria (MIR) apostou no campo como foco da insurgência, conformando o Movimento Campesino Revolucionário, que deslocaria a maior parte de seus elementos para a zona mapuche (TINSMAN, 2009, p. 157).

Quanto aos movimentos dos proprietários, as mudanças também foram rápidas. Sob a direção de Manuel Valdes, foi criada a Confederação de Empregadores Agrícolas. A SNA trocou o desgastado Luiz Marín pelo ex-deputado Hugo Zepeda Barrios, que passou a investir pesado em propaganda e que buscava uma aproximação com os sulistas tendo em vista que todos eram igualmente proprietários e que agora sentiam o peso das greves, das ocupações de terras, dos baixos preços para seus produtos, dos altos custos para gerá-los e das desapropriações (OSZLAK, 2016, p. 278).

Nas eleições de 1965, a Democracia Cristã conquistara maioria absoluta no parlamento, deixando as forças de direita em terceiro lugar. Aglutinadas no Partido Nacional, essas forças vieram a crescer sobremodo nas eleições legislativas de 1969, podendo alimentar esperanças para as eleições presidenciais de 1970. Do ponto de vista da direita, seria mesmo necessário um retorno ao Palácio de La Moneda. Certamente, a atuação do governo de Eduardo Frei não se limitou à reforma agrária e à sindicalização rural, promovendo também um forte investimento na plantação de frutas, que seria colhido durante o pinochetismo. Em agosto de 1969, quando os democratas-cristãos lançaram Radomiro Tomic para presidente, ficou claro para a SNA e para o CAS - este sob a direção de Domingo Durán - que os votos buscados por eles, teriam de ser disputados com a esquerda e não com a direita. Ocorre, portanto, uma aceleração das expropriações de terra em 1970. A reação proprietária tornou-se então mais radical, expressando-se pelo assassinato, na província de Linares, de Hernán Mery Fuenzalida, funcionário da CORA, que havia ido tomar posse material de uma fazenda expropriada. O assassinato foi louvado no parlamento pelo deputado do Partido Nacional, Victor Carmini, que exclamou: "é apenas o primeiro morto!” (AVENDAñO, 2017, p. 254).

Após quatro milhões de hectares expropriados e um movimento campesino crescente, em setembro de 1970, foi realizada a eleição presidencial. Salvador Allende venceu por margem mínima e teve a vitória confirmada no Congresso Nacional após um acordo com a Democracia Cristã. Para os proprietários, essa situação representava defender-se de um ataque final: num primeiro momento procuraram conversar com Allende e o presidente da SNA, 
Benjamin Matte, foi a Cuba tentar vender produtos chilenos para o novíssimo parceiro comercial, já que o novo governo restabelecia o comércio com a ilha socialista. Mas a resposta do novo Ministro da Agricultura, Jacques Chonchol, a uma consulta feita pela SNA não poderia ser mais clara: o governo apoiaria cooperativas mas não sociedades anônimas disfarçadas de cooperativas, a pequena e média propriedade estariam garantidas desde que estivessem em conformidade com as necessidades nacionais e, finalmente, os agricultores poderiam ter voz, todavia as políticas públicas seriam decididas pelos conselhos comunais campesinos, organizados a partir de janeiro de 1971. Deste modo, aquele não apenas não era o seu governo, era o governo contra seus interesses, não havendo espaço para negociação.

Quanto aos movimentos camponeses, antes mesmo do governo de Salvador Allende ser eleito, militantes do Movimiento de Izquierda Revolucionaria (MIR) chegavam à província de Cautín para mobilizar os mapuches e, em seus termos "levar consciência a eles", embora não houvesse necessidade de explicar-lhes que deviam lutar por suas terras, pois faziam isso desde que as haviam perdido. Nos primeiros meses do governo de Salvador Allende, multiplicaram-se as corridas de cerco, ou seja, retiravam as cercas que reduziam as comunidades indígenas. Allende enviou Chonchol ao Sul e muito do que foi feito pelos mapuches foi aceito oficialmente. Além dos oficiais conselhos comunais campesinos criados pelo governo, os "miristas" organizaram os conselhos comunais campesinos pela base, buscando incorporar um maior número de militantes mapuche e controlar o processo de reforma agrária em nível local, a fim de desenvolvê-lo autonomamente face ao Estado e reforçando o que pensavam ser o poder popular contra o poder burguês (HERNÁNDEZ, 2016, p. 98).

O governo Allende buscou incorporar os não assentados no processo de reforma agrária, a qual havia sido pensada para aqueles que, mal ou bem, já tinham acesso à terra. Desse modo, buscou-se a criação dos Centros de Reforma Agrária, que agregaria o trabalho coletivo dos que estavam participando do processo. Entretanto, é preciso recordar que os campesinos ligados à Democracia Cristã acreditavam na necessidade de terem sua parcela individual de terra. Logo buscaram reivindicar a concessão de lotes nesta modalidade. Isso permitiu, a médio prazo, que os terratenentes da Sociedade Nacional de Agricultura ampliassem suas bases, uma vez que não apenas os fazendeiros expropriados ficaram sem direito à reserva de terra ${ }^{12}$, mas também o pequeno e o médio cultivadores, que temiam perdêla. Também, o beneficiário da reforma temia o "patrão-estado", e até mesmo o engenheiro agrônomo ou florestal que, descontentes, reclamavam do salário pago pelo Estado.

O crescimento das ocupações de terra multiplicava os confrontos. Os irmãos Baraona, por exemplo, sequestraram o motorista do deputado Joel Marambio, do Partido Socialista, e foram presos. Poucas semanas depois, suas terras foram expropriadas e o patriarca Jorge Baraona enfartou, morrendo durante a ação estatal. Incidentes como estes catalisavam a mobilização terratenente, que se apresentava como defensora da legalidade (OSZLAK, 2016, p. 257; OVALLE, 2013, p. 213-235).

No que tange ao funcionamento do setor reformado, como lembra Bengoa (2015, p. 234), a imagem de que as áreas reformadas não produziam e que ficou gravada na memória da maioria da população chilena, precisava ser redimensionada uma vez que, de acordo com as estatísticas, percebia-se uma disponibilidade de alimentos para o mercado interno maior naqueles anos, apesar da presença de uma relativa escassez de produtos resultante da ampliação da demanda decorrente do aumento dos salários. De todo modo, as memórias elaboradas pelos proprietários depois de 1973 reafirmam a todo tempo a impossibilidade de uma reforma agrária, pela incapacidade campesina (OVALLE, 2013, p. 215).

\footnotetext{
${ }^{12}$ A reserva era prevista na lei de reforma agrária e o proprietário poderia escolher um pedaço de terra para manter. Na prática, muitas vezes, isso não ocorreu.
} 
A polarização social no Chile crescia a cada expropriação, que atingia, muitas vezes, médias propriedades. Em dezembro de 1971, começaram os panelaços, explorando a presença do líder cubano Fidel Castro no país e a SNA lançou a Frente Nacional da Empresa Privada (FRENAP). Em maio, época da semeadura, foi lançada uma discreta campanha para que os grãos não fossem semeados. Em setembro, a Rádio Agricultura, da SNA, foi suspensa por se recusar a participar de uma transmissão em cadeia nacional, decisão, por sinal, impensável em tempos de Pinochet, mas defendida pela SNA como liberdade de expressão contra o governo de Allende. Em outubro, explode a greve dos caminhoneiros, que paralisou o país enquanto grupos como o MIR, o Partido Comunista Revolucionário e setores socialistas pediam o aprofundamento da revolução. A partir de então, o governo passa a lutar por sua sobrevivência. A SNA coordenou o apoio à greve dos caminhoneiros que acabou se convertendo num lockout patronal (OSZLAK, 2016, p. 314). Enquanto isso, ao sul do país, o movimento Patria e Libertad promovia atentados à bomba, incêndios e assassinatos de lideranças de esquerda. Nos meses seguintes, armas vindas do Brasil abasteciam a luta armada, numa espécie de paraguerrilha (ÓRDENES, 2018, p. 224).

A partir do impasse representado pela eleição de março de 1973, na qual nem o governo conseguiu maioria do Congresso, nem tampouco a oposição obteve os dois terços necessários ao Impeachment, a oposição passa a defender abertamente um golpe militar. Não é nosso objetivo discutir os antecedentes imediatos ao golpe empresarial-militar de 11 de setembro de 1973. Para os limites deste trabalho basta dizer que em agosto, em regiões como Cautín, camponeses mapuches já eram torturados sob pretexto de busca de guerrilheiros. Quando o Palácio de La Moneda foi bombardeado, o aparato repressivo, portanto, já estava funcionando.

\section{CAMPESINOS E TERRATENENTES FACE A AUGUSTO PINOCHET (1973-1990)}

Além da vigorosa repressão que se abateu sobre o campo nas primeiras horas do golpe de Estado liderado pelo general Pinochet, os líderes do movimento não tinham clareza a respeito do que fariam com seu país a partir do dia 12 de setembro. Supervalorizando a capacidade do adversário - como um século antes o exército fizera com os araucanos -, a vitória fulminante do golpe pode ter surpreendido até os vencedores. No campo era fácil pisar com coturnos em camponeses para que denunciassem supostos guerrilheiros, tal qual no Fundo Agua Fría, província de Maule, como me contou dona Alicia Muñoz. As torturas e desaparecimentos eram logo denunciados no exterior, embora houvesse camponeses aglutinados na Democracia Cristã, prontos a dar declarações favoráveis ao novo regime (SILVA, 1987, p. 32).

As mudanças no setor agrário tinham sido longas demais. A reforma durou onze anos e ainda era popular, apesar do problema do desabastecimento. Assim, num primeiro momento, o objetivo foi ceder em pequenos lotes aos cultivadores, que já as ocupavam, terras das áreas reformadas que não tivessem sido devolvidas aos antigos proprietários, nem redistribuídas a grupos econômicos ligados à nova ordem ${ }^{13}$. Atendia-se a uma reivindicação de parcela expressiva do campesinato e, ao mesmo tempo, quebrava-se a noção de cooperativismo: "não seremos uma nação de proletários, mas de proprietários" (SILVA, 1987, p. 45). Essa mesma noção seria estendida às terras mapuches, a partir de 1978. O governo militar procurou demarcar as fronteiras de cada pequeno lote e cedê-lo individualmente.

\footnotetext{
${ }^{13}$ Vale salientar que cerca de um terço das terras foi devolvido aos proprietários antigos. Houve terras cedidas, por exemplo, a empresas florestais ao Sul. De acordo com Ulloa, cerca de 45 por cento dos beneficiários permaneceram com as terras, mas a maioria acabaria perdendo-as face à falta de apoio técnico-financeiro após o desmonte das estruturas estatais previstas para apoiar o processo reformista (ULLOA, 2006, p. 265).
} 
Embora houvesse fortes protestos, essa demarcação foi encarada, por muitos mapuches, como algo positivo, afinal agora a terra era deles (BENGOA, 2014, p. 254).

Entretanto, é preciso lembrar que a terra só era cedida em lotes individuais a quem fosse bem visto pelo regime. Além disso, o crédito do Banco do Chile e sua função de importação de fertilizantes que regulava os preços desses produtos e a Empresa Comercial Agrícola, cujo objetivo era garantir um preço mínimo para o produto vendido pelo camponês e regulá-lo ao consumidor, não mais existiam.

De acordo com Patricio Silva, três setores disputaram a preeminência no Ministério da Agricultura durante os primeiros meses do regime: aqueles vinculados ao presidente Jorge Alessandri, que defendiam algum apoio aos parceleiros; os gremialistas, sob influência dos carabineiros, que buscavam algum sistema cooperativista; e, finalmente, os neoliberais. Estes últimos acabaram triunfando não só no Ministério da Agricultura, mas em todo processo, transformando o Chile em uma espécie de laboratório de experiências que seriam desenvolvidas em todo continente nas décadas seguintes (SILVA, 1987, p. 65).

Num primeiro momento ainda havia alguma proteção aos gêneros agrícolas, mas rapidamente a concorrência de bens estrangeiros reduziu o preço para o produtor nacional. Os produtores de leite do Sul, por exemplo, liderados por Domingo Durán, protestaram em 1977 contra os baixos preços do leite e contaram com o apoio da indústria leiteira, diferentemente dos que plantavam arroz e beterraba, que não tiveram nenhum auxílio de outros grupos sociais. Até mesmo a produção frutífera, que se tornaria importantíssima, perdeu, num primeiro momento, um de seus principais importadores, o Brasil, que passara a produzir maçãs (SILVA, 1987, p. 98.)

Embora tradicionalmente representasse os produtores do Chile central, a construção da unidade com os demais setores proprietários, durante o governo de Allende, levou os líderes da SNA a buscar a representação de todos os demais setores rurais. Desta forma, tentaram agregar os diversos ramos empresariais no apoio a Pinochet, já que não mais sofriam expropriação de suas terras nem ocupação pelos camponeses e as greves deixaram de acontecer. Desse modo, em 1980, apoiaram a constituição imposta pelo regime, via plebiscito.

Entretanto, o ano de 1982 trouxe uma nova crise no mercado mundial e o anúncio de que o México não mais pagaria sua dívida externa acarretou graves problemas, levando ao risco de falência de muitas fazendas. Um articulista do Jornal El Mercúrio, em tom irônico, perguntou se os proprietários estavam com saudades da reforma agrária. Domingo Durán, dirigente da Confederación de Productores Agricolas, entidade de proprietários rurais do Sul do país, chamava de reforma agrária aquelas visitas de agentes de bancos para cobrar dívidas.

O governo militar passou então a desenvolver uma política de apoio aos setores em crise, abandonando o fundamentalismo neoliberal, uma vez que era necessário garantir a aliança, que desde o começo sustentou o regime. Assim, em 1978, Alfonso Márquez de La Plata, presidente da SNA à época do golpe, foi o primeiro ministro civil da Agricultura (nos primeiros anos do regime a maioria dos Ministérios era ocupada por militares).

Nos anos após a crise, o setor proprietário manteve-se alinhado a Pinochet e, em 1987, quando da campanha em favor do não como resposta ao novo plebiscito previsto na constituição ${ }^{14}$, foi realizado um seminário sobre reforma agrária e todos os fantasmas do passado foram trazidos à tona. Falar em reforma agrária nos moldes dos anos 1960 seria um contrassenso, pois era preciso manter a segurança pinochetista. Após a derrota eleitoral do regime, os líderes da SNA buscaram manter-se fiéis ao que entendiam ser seu principal legado: ordem, baixa mobilização sindical e paz para produzir (AVENDAÑO; ESCUDERO,

\footnotetext{
${ }^{14}$ A constituição de 1980 dava mais dez anos de mandato a Pinochet, que terminariam em março de 1990. Em 1988, haveria um plebiscito que perguntaria se o povo queria dar mais oito anos de mandato ao ditador. Mesmo que perdesse, Augusto Pinochet ficaria mais oito anos como comandante do exército e, depois de 1998, teria uma senatoria sem precisar disputar eleições.
} 
2016 , p. 42) ${ }^{15}$. Se entidades como a SNA normalmente apoiavam o regime, o que dizer dos movimentos camponeses? Aqueles que foram favoráveis a Allende sofreram o peso da repressão. Dona Alicia Muñoz conta que, de fato, não sabiam o que os maridos estavam fazendo nas ocupações de terra, posto que eles não lhes contavam, face ao machismo reinante na sociedade. Entretanto, o impacto dos desaparecimentos dos homens foi sentido nas primeiras horas. Para Tamara Carrasco e René Moreno, o objetivo fundamental da repressão feita pelos terratenentes, em parceria com carabineiros e membros das forças armadas, não era apenas político, mas principalmente social, tendo em vista que queriam mostrar ao camponês que ele simplesmente não tinha o direito de falar de igual para igual com o seu patrão. Por isso, e para mostrar quem mandava, o treinamento da Escola Militar no verão daquele ano foi feito em áreas predominantemente mapuches (CARRASCO, 2012, p. 53; MORENO, 2009, p. 65; BENGOA, 2014, p. 254).

Um dos principais apoios recebidos pelos camponeses foi o da ala progressista da Igreja Católica. O bispo de Santiago, Dom Raúl Silva Enriques, organizou, nas primeiras horas do golpe, a Comisión Pro Paz e, mais tarde, o Vicariato de la Solidariedad, criando, desse modo, um departamento campesino. Dona Alicia, na citada entrevista, me conta que a primeira atividade pública foi organizar, em 1977, o Festival do Canto Campesino por meio da Rádio Chilena, pertencente à Igreja Católica. Entretanto, a partir de 1978, várias confederações, inclusive a Ranquil, tornaram-se ilegais. A repressão ainda se fazia vigorosa e o novo ministro do trabalho, Sérgio Fernández, chegou a decretar a exclusão de todos os sindicalistas e a convocação para eleições sindicais, em três dias. No exterior, protestos serviram para conter um pouco a força da repressão, uma vez que houve uma ameaça de bloqueio nos transportes aéreos e marítimos para o Chile. A nova lei sindical, porém, não era muito melhor tendo em vista que os sindicatos deveriam ser formados por empresa e as greves seriam praticamente proibidas. Alicia diz também que cada reunião sindical precisava contar com a autorização do prefeito local, mediante a apresentação de uma pauta, além de ser necessário entregar a ata da reunião posteriormente. Evidentemente, nem pauta nem ata eram verdadeiras.

Eidi Tinsman observa a feminização do trabalho rural especialmente no setor frutícola e as duras condições de vida que passavam as mulheres. Como consequência desses processos, os incipientes sindicatos também tiveram maior presença feminina, ampliando as possibilidades para discussão de temas como o cuidado das crianças e reivindicações por creches, embora, como lembra Alicia, os dirigentes homens dos sindicatos tivessem pouca sensibilidade para o tema.

Entre 1979 e 1982, a Igreja Católica organizou a Comisión Nacional Campesina, que depois dividiu-se. As velhas confederações buscaram rearticular-se: Ranquil (inicialmente Surco), vinculada aos comunistas, Newen (socialista) e as velhas entidades ligadas à Democracia Cristã, que mesmo não sendo proibidas tinham pouca presença no movimento camponês (GÓMES, 1985, p. 27; MEDEL, 2014, p. 21).

As organizações rurais não participaram vivamente dos protestos contra a ditadura que marcaram o país entre 1983 e 1986. Os panelaços, os combates de rua e pequenas ações de guerrilha urbana estiveram longe do meio agrário. No campo, além da repressão, a precarização das relações de trabalho, com a possibilidade da perda do emprego a qualquer momento, era um poderoso instrumento de contenção social. Foi possível juntar-se às forças opositoras para tentar garantir a vitória contra o regime por meio do plebiscito em 1988, após o frustrado ataque armado contra Pinochet em 1986. Apesar da vitória do NÃO, não se poderia dizer que o modelo econômico e político pinochetista tivesse hipóteses de se desagregar.

\footnotetext{
${ }^{15}$ O plebiscito realizado no Chile em 1980 não teve supervisão internacional e a oposição pôde realizar apenas
} um ato de campanha em um teatro fechado. 
Refletindo sobre o plebiscito de 1988, é importante retornarmos ao tema mapuche, tendo em vista que o decreto-lei que anunciava a desagregação de suas comunidades provocou viva reação nas áreas onde sua presença era expressiva. Criaram-se, em 1979, os centros culturais mapuche, mais tarde chamados Asociación Gremial de Campesinos y Artesanos Mapuche. ntretanto, não foi possível impedir a divisão destas comunidades, que acabaram desagregadas. Os mapuche tinham tentado, de acordo com Bengoa (2014, p. 259), unir-se aos campesinos no início dos anos 1970 para recuperar sua terra. Bem ou mal, agora tinham uma garantia da propriedade, ainda que persista a luta em nossos dias, pois muitos ficaram excluídos do acesso à terra. Por outro lado, o regime militar, à moda neoliberal, desenvolveu políticas de subsídio a camponeses, em áreas como Cautín, por meio de aposentadorias, pensões para viúvas e programas comunais agrícolas.

A Araucanea, que agrega províncias como Cautín, foi a única região onde Augusto Pinochet venceu, obtendo mais de oitenta por cento em certas comunidades. $\mathrm{Na}$ eleição seguinte, os candidatos de direita, que enfrentaram a oposição liderada por Patrício Aylwin, obtiveram cerca de setenta por cento dos votos. O pinochetismo conseguia construir uma base social, além das elites e dos setores médios urbanos (BENGOA, 2014, p. 245).

Deste modo, o ciclo pinochetista na presidência (não podemos dizer no poder, pois as forças armadas continuavam desemprenhando importante papel na vida política do país), terminava com um campo bastante modificado. O sindicalismo, que foi praticamente abortado nos anos quarenta e que floresceu a partir da ascensão de Eduardo Frei, encontrava-se desagregado. $\mathrm{O}$ velho latifúndio com relações paternalistas também não mais existia. $\mathrm{O}$ camponês ou a camponesa moravam agora nos vilorios, pequenas cidades, de onde partiam para o trabalho. Quase um século depois, a agricultura voltou a exportar, nos moldes neoliberais, produtos florestais (a partir de áreas do Sul, concedidas às vezes a favoritos do regime) e frutas frescas para a contra estação no Hemisfério Norte, porém o cobre continuava a ser o "soldo do Chile", na feliz expressão do presidente Salvador Allende. A década de 1990, contudo, se iniciaria sob o signo de uma democracia liberal, sob tutela militar.

\section{CONCLUSÃO}

Como em toda a América Latina, a Revolução Cubana despertou as mais profundas esperanças e os mais apavorantes temores em amplas camadas sociais do Chile. Para os setores de esquerda, muitas vezes originários da classe média, ela era a vitória possível, de acordo com o mito de que uma dezena de guerrilheiros derrubaria um exército. Para os setores moderados das elites políticas, a reforma agrária, seguindo a receita de policy makers estadunidenses, era a vacina para evitar o desastre. Para as elites proprietárias, que eram o alvo destes processos, a reforma era a tradução de tudo o que não precisavam. Desde a crise de 1929, acreditavam pagar o preço da industrialização. $\mathrm{Na}$ verdade, muitos destes proprietários, em especial os do Chile central, apareciam pouco em suas fazendas, mas agora começavam a valorizá-las. No Sul, inicialmente compraram o discurso da modernização, acreditando na lenda de que eles mesmos tinham construído aquela região e de que antes deles nada existia a não ser índios iletrados. Mas os índios iletrados em questão mantinham a memória de muita luta e, nas palavras de José Bengoa, os "caciques ricos" cultivavam suas terras e quando as razias promovidas pelo exército, a partir de 1866 tornaram-se mais agudas, passaram a criar gado. Seus descendentes lembravam muito bem onde se localizava a terra que os colonos haviam cercado. A reforma agrária não foi pensada para eles, mas sentiram que poderiam agarrar o seu momento. O camponês do Chile central, visto por seu patrão como "índio", no pior sentido da palavra, também sonhou que poderia ser o proprietário de sua terra. Talvez não quisesse ser o grande patrão, mas um "patrón en chiquito", tendo em 
vista que muitos contrataram gente para trabalhar nos assentamentos organizados no governo de Frei, como lembra Bengoa (BENGOA, 2015, p. 287).

Sonhos para uns, pesadelos para outros, o processo começou a se desenvolver em 1962. Thompson nos mostra que a lei é, antes de tudo, o espaço em disputa e a vitória não está garantida (THOMPSON, 1997, p. 231). Se os planejadores do governo de Jorge Alessandri pensaram aprovar uma lei de reforma, só por "saludo a la bandera", estavam completamente equivocados. A partir do governo de Eduardo Frei, o processo acelerou-se. A reforma era quase um consenso, mas a questão era como fazê-la. Diferentemente do Brasil, onde isso era discurso, já que os interessados em sua não realização se encastelaram na burocracia do governo Castello Branco, no caso chileno a reforma foi acelerada por Eduardo Frei e disparou no governo Allende. Em menos de três anos houve mais expropriações do que em seis anos do governo de Frei. Como vimos, ficou a memória da disfuncionalidade, mas provavelmente uma análise mais acurada poderá levar a outros resultados.

Quando sobreveio o golpe empresarial-militar de 1973, não houve como simplesmente voltar a 1962, tendo em vista que as mudanças tinham sido grandes demais, no sentido de que fazendeiros se exilaram e terras divididas passaram a outras mãos. O trabalho iniciado no governo Frei e mantido no de Salvador Allende, no tocante à plantação de frutas, continuaria a ser desenvolvido e colhido por Pinochet. Como em todo continente, o êxodo rural seguia, mas não mais para fábricas. O Chile se desindustrializou.

A receita neoliberal era clara e o país de Violeta Parra inseriu-se no mercado internacional rapidamente, mas ficou exposto a crises econômicas, como a de 1982. Passada a era pinochetista, as elites empresariais articuladas na SNA e em outras organizações continuaram defendendo o legado do regime. Quando o Mercosul pôde finalmente tecer acordos comerciais com o Chile, as elites, evidentemente, resistiram, mas aquilo que para eles era um legado de segurança deixado pelo regime militar deveria ser mantido. Daí os protestos mapuche, na luta pela recuperação de suas terras, serem interpretados como "terrorismo" pelos dirigentes da SNA.

Quanto aos movimentos campesinos, a luta continuaria nos anos noventa. Para Alícia Muñoz, as diversas confederações têm uma atitude exageradamente moderada e são pouco sensíveis aos temas femininos. Daí a criação da Associación de Mujeres Rurales, mais tarde indígenas. Tais confederações continuam sustentando a bandeira de uma nova reforma agrária, porém não mais calcada no produtivismo dos anos 1960, mas na produção de alimentos saudáveis e gerados localmente. De sua capacidade de mostrar a outros setores que esse objetivo não se limita ao campesinato, depende a possibilidade de efetivar tais resultados. Por enquanto os terratenentes continuam demonstrando que os objetivos válidos para toda sociedade são os seus. A memória camponesa é a da perda de milhares de vidas humanas nos incontáveis massacres enquanto a memória terratenente ainda lamenta a perda de propriedades. São memórias que combatem pela hegemonia na sociedade chilena.

\section{REFERÊNCIAS}

AVEndaño, Octavio. Los Partidos Políticos Frente a la cuestión Agraria em Chile. Santiago: Lom, 2017.

AVENDAÑO, Octavio; ESCUDERO, María Cristina. Elitismo y Poder Gremial en la Sociedad nacional de Agricultura. Revista Ciencias Sociales. Santiago do Chile: Universidade Católica de Chile, n. 20, 2016.

BENGOA, José. Historia Rural de Chile Central. Santiago. Lom Editores, Tomo 2, 2015. 
BENGOA, José. Mapuche, Colonos y Estado Nacional. Santiago, Catalónia, 2014.

CARRASCO, Tamara-Chimena. El campesinado entre Frei y Pinochet. Testimonios de Ia Reforma Agraria en tres momentos: comunitaria, socialista y contrarreformista. Huelquén, Paine (1967-1976). Santiago: Universidad de Santiago, Tesis de Magister, 2013.

CORRÉA, Martín. La Reforma Agraria em las Tierras Mapuches. Santiago: Lom, 2005.

GÓMES, Sergio. Movimiento Campesino en Chile. Santiago: Flacso, Documento de Trabajo 246, 1985.

HERNÁNDEZ, Ovídio Cárcamo. Movimiento Campesino Revolucionario y Consejos Comunales Campesinos de base. Una experiencia de Poder Popular en Chile. Revista Desato. Barcelona, Universitat autónoma de Barcelona, n. 52, p.191-204. 2016.

LOVEMAN, Brian. The Struggle in the Countryside: Politics and Rural labor in Chile 1919-1973. Indiana, 1976.

MEDEL, Rodrigo. Movimiento Sindicalista Campesino en Chile. 1924-2000. Santiago, Sipistra, n. 2, 2014.

MORENO, Juan René Maureira. Enfrentar con la Vida a La Muerte: Historia y Memorias de la Violencia y el terrorismo de Estado em Paine. Santiago, tesis de Licenciatura en Historia, 2009.

OLIVARES, María Angelica Illanes. Movimiento en la tierra: Luchas campesinas, resistencia patronal y política social agraria. Chile, 1927-1947. Santiago: Lom, 2019.

ÓRDENES, Mathias. Cuando la Mano de Obra se Subleva: estrategias terratenientes durante la reforma agraria chilena (1964-1973). Revista História Agraria, Bacelona: Sociedad de Historia Agraria, p. 201-230. 2018.

OSZLAK, Oscar. La Trama Oculta del Poder: Reforma Agraria y Comportamiento Político de Los Tierratenientes Chilenos (1958-1973). Santiago: Lom, 2016.

OTERO, Luiz Gamarra. Un Testemuñeo Personal. In: BARRANTES, S. (org.). A Trinta y Ocho Años de la Reforma Agraria. Lima: Fundación Herbert Bustamante de la Fuente, 2007.

OVALlE, María Angelica; VICUÑA, Angela. La Reforma Agraria Chilena: Testemuneo de sus Protagonistas. Santiago: Memoriter, 2013.

PERALTA, José. (org) A Desalambrar: Historia de Mapuches e Chilenos em la Lucha por la Tierra. Santiago: Lom, 2006.

PÉREZ, Cristian. La Guerrilla Rural en Chile. La Batalla por el Fundo San Miguel. Estudios Públicos, Santiago: Sociedad de Estudios Públicos, n. 78, oct./dic. 2000.

ROJAS, Nestor Orlando Espinosa. La política socialista en torno al agro en Chile. 19321939. Maldivia: Instituto de Historia y Ciencias Sociales, Tesis de Licenciatura, 2015. 
SEGUEL, Mathias Calderon. Memorias de la Reforma Agraria: La lucha por la Tierra en el Valle de Longotoma. Santiago: Lom, 2012.

SILVA, Patricio. Estado, Neoliberalismo y Política Agraria em Chile (1973-1981). Amsterdan: Sedla, 1987.

THOMPSON, Edward Palmer. Senhores e Caçadores. São Paulo: Companhia das Letras, 1997.

TINSMAN, Eidi. La Tierra para El Que la Trabaja: Género, Sexualidad y Movimientos Campesinos em la Reforma Agraria Chilena. Santiago: Lom Editores, 2009.

ULLOA, Roberto Santana. Agricultura Chilena em EI Siglo XX: Contextos, Actores Y Espacios Agrícolas. Santiago: Dirección de Bibliotecas, Archivos y Museos, 2006.

VASCONCELOS, Joana Salen. Reforma Agrária e Socialismo na América Latina. In: RIBEIRO, Vanderlei Vazelesk; SECRETO, Verónica. Agrarismos: Sociologia e História do Rural Contemporâneo. Rio de Janeiro: Mauad, p. 237-257. 2017. 